\title{
Early detection of first-time slope failures using acoustic emission measurements: large-scale physical modelling
}

\author{
A. SMITH*, N. DIXON* and G. J. FOWMES*
}

\begin{abstract}
Early warning systems for slope instability need to alert users of accelerating slope deformation behaviour to enable safety-critical decisions to be made. This study shows that acoustic emission (AE) monitoring of active waveguides (i.e. a steel tube with a granular backfill surround installed through a slope) can both detect shear surface development and quantify increasing rates of movement during slope failure, thereby providing an early detection of slope instability. A large-scale physical model was designed and built to simulate slope failures on elements of soil, through which full-scale active waveguides were installed. A shear surface develops in each test and the sliding mass accelerates during failure, reaching velocities greater than $300 \mathrm{~mm} / \mathrm{h}$ and shear deformations of $50 \mathrm{~mm}$. Continuous measurements were obtained to examine the behaviour of active waveguides subjected to first-time slope failure dynamics (i.e. development of new shear surfaces and accelerating deformation behaviour). Comparisons with continuous subsurface deformation measurements show that AE detection began during shear surface formation, and AE rates increased proportionally with displacement rates as failure occurred. Empirical AE rate-slope velocity relationships are presented for three granular backfill types, which demonstrate that generic AE rate-slope velocity relationships can be obtained for groups of backfill types; these relationships allow displacement rates to be quantified from measured AE rates to provide early detection of slope instability.
\end{abstract}

KEYWORDS: deformation; failure; field instrumentation; landslides; monitoring; slopes

\section{INTRODUCTION}

Shear surfaces can develop in slopes formed of strain-softening materials (e.g. overconsolidated clay) after very small deformations (millimetres) (Skempton, 1985; Bromhead, 2004). Shear zones develop when the shear stress exceeds the peak shear strength locally within the slope, causing reductions in strength to occur. These shear zones propagate through the slope, developing a continuous shear surface, leading to slope failure (Skempton, 1964; Skempton \& Petley, 1967; Chandler, 1984; Leroueil, 2001). These first-time failures can have high post-failure velocities and experience large displacements, leading to potentially catastrophic consequences. During this failure process, the rate of movement increases by orders of magnitude; from the gradual development of a shear surface producing low velocities, to the high velocities that are reached after the shear surface forms, shear strength reduces and failure occurs. Early warning of this process (i.e. shear surface development and accelerating deformation behaviour) is critical to enable evacuation of vulnerable people and timely repair and maintenance of critical infrastructure.

The Selborne cutting stability experiment (Cooper et al., 1998) provides a detailed example of a first-time failure. The progressive failure process began at the toe of the slope shortly after the cutting was formed, and the shear surface retrogressed up-slope leading to failure 596 days later. Pore-water pressure recharge (i.e. leading to increased porewater pressures within the body of the slope) was initiated on

Manuscript received 7 September 2015; revised manuscript accepted 8 July 2016. Published online ahead of print 19 September 2016. Discussion on this paper closes on 1 July 2017, for further information see $\mathrm{p}$. ii.

Published with permission by the ICE under the CC-BY license. (http://creativecommons.org/licenses/by/4.0/)

$*$ School of Civil and Building Engineering, Loughborough University, Leicestershire, UK. day 400 , and at this time shear surface displacements of a few millimetres were measured near the toe of the slope. Between days 584 and 589, the slope had accelerated and was moving at an average rate of $0.6 \mathrm{~mm} / \mathrm{h}$. This accelerating behaviour continued and the rate of movement increased from $4 \mathrm{~mm} / \mathrm{h}$ to $58 \mathrm{~mm} / \mathrm{h}$ on day 596 when the instruments became damaged and no longer readable, due to tens of millimetres of accumulated displacement. The slope continued to accelerate until failure occurred.

Researchers over a period of several decades have developed slope monitoring strategies using measurement and quantification of acoustic emission (AE) generated by deforming soil (e.g. Koerner et al., 1981; Chichibu et al., 1989; Nakajima et al., 1991; Rouse et al., 1991; Fujiwara et al., 1999; Dixon et al., 2003, 2015a; Smith et al., 2014a). These approaches typically employ waveguides (e.g. steel tubes) to provide low attenuation propagation paths for $\mathrm{AE}$ to be transmitted from the depth of the shear surface to ground level. Monitoring strategies have also been developed using 'noisy' backfill material placed around the waveguide that generate quantifiable $\mathrm{AE}$ (i.e. $\mathrm{AE}$ is measured from the backfill material and not from the host slope material) when deformed by the host slope, and these are termed 'active' waveguides (e.g. Dixon et al., 2003; Smith \& Dixon, 2015). AE monitoring of active waveguides offers many benefits over traditional deformation monitoring techniques, which include: the subsurface materials are low in cost and easily sourced, which enables them to be used widely both in developed and developing countries; continuous and realtime measurements can be provided at relatively low cost because of low-cost electronics (in comparison to in-place inclinometer systems); and they continue to operate at larger displacements (>400 $\mathrm{mm}$ of shear surface displacement) than other conventional techniques (Dixon et al., 2015b).

Active waveguides are installed in boreholes, or retrofitted inside existing inclinometer or standpipe casings, that intersect existing or potential shear surfaces beneath the slope, 


\begin{tabular}{|c|c|c|c|c|}
\hline $\begin{array}{l}\text { AE generated by active } \\
\text { waveguide in response to } \\
\text { slope movement (a) }\end{array}$ & $\begin{array}{l}\text { Signal processing and } \\
A E \text { rate quantification by } \\
\text { measurement node }(b)\end{array}$ & $\begin{array}{l}\text { Quantification of slope velocity } \\
\text { using calibration AE rate- } \\
\text { velocity relationship }\end{array}$ & $\begin{array}{l}\text { Classification of slope velocity } \\
\text { using the standard Cruden \& } \\
\text { Varnes (1996) scale (c) }\end{array}$ & $\begin{array}{l}\text { Send warning to decision } \\
\text { maker to allow action to } \\
\text { be taken }\end{array}$ \\
\hline
\end{tabular}

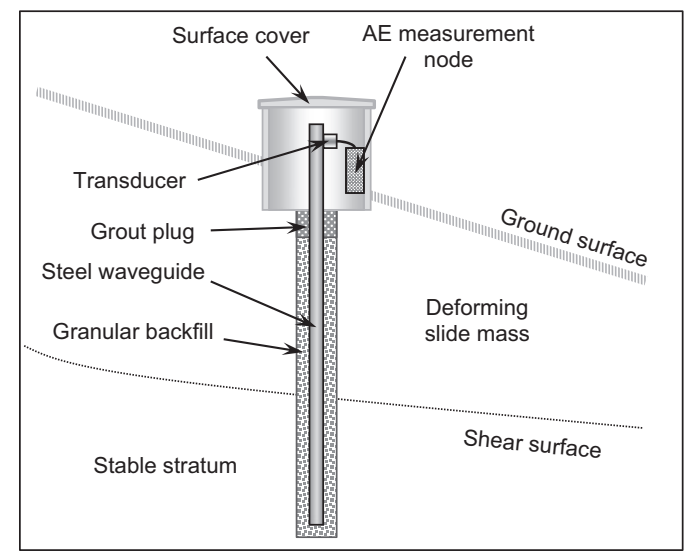

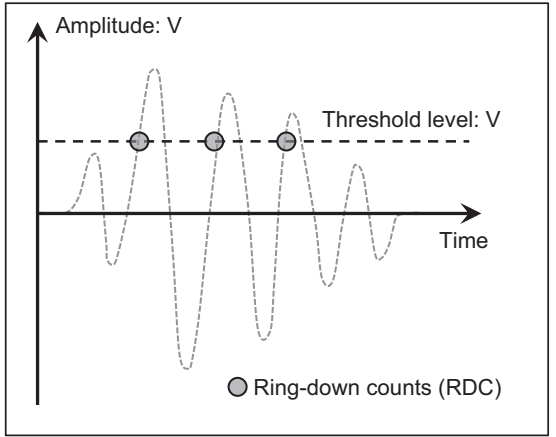

(b)

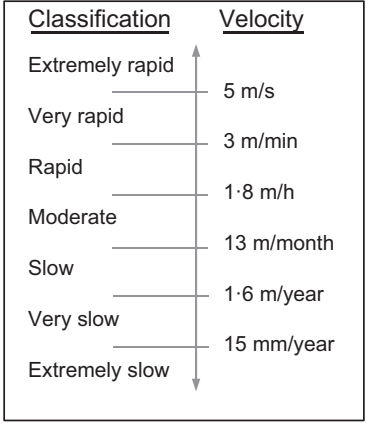

(c)

(a)

Fig. 1. Operation schematic diagram of the AE active waveguide early warning system. (a) and (b) are modified after Smith et al. (2014a)

and they comprise the composite system of a steel tube with a granular backfill surround (Fig. 1). As the host slope deforms, the active waveguide deforms, and this causes particle-particle and particle-waveguide interactions to take place, which generate the AE. AE generation mechanisms include friction (rolling and sliding friction) and collisions (e.g. particle contact network rearrangement and release of contact stress as interlocking is overcome and regained) (Lord \& Koerner, 1974; Koerner et al., 1981; Michlmayr et al., 2013; Michlmayr \& Or, 2014).

Trials in reactivated slopes have established that there is a direct relationship between slope displacement rates and active waveguide-generated AE rates (Smith et al., 2014a, 2014b; Smith, 2015; Dixon et al., 2015a, 2015b). To date, these trials have been in slopes with an already formed and defined shear surface at (or near) residual shear strength that move in surges of modest speed $(<0.3 \mathrm{~mm} / \mathrm{h})$ and travel $(<6 \mathrm{~mm})$ in response to rainfall-induced pore-water pressure elevations. Generated AE rates are proportional to applied displacement rates because an increasing rate of deformation (i.e. in response to increasing slope velocity) generates an increasing number of particle-particle and particle-waveguide interactions per unit time. Each particle interaction generates transient AE events, which combine and propagate along the waveguide where they are monitored at the ground surface.

This study was conducted to investigate the potential of using active waveguide-generated AE measurements to provide early detection of first-time slope failure. The objectives of the study were: to investigate the use of AE measurements to detect accelerating deformation behaviour in a model that applies a realistic shear mechanism to full-scale active waveguides; to establish relationships between applied displacement rates and measured AE rates for applied displacement rates greater than those measured in field trials to date (i.e. $>0.3 \mathrm{~mm} / \mathrm{h}$ ); to investigate the use of the technique to detect the formation of new shear surfaces; and to investigate the influence of different backfill materials on the AE generated by active waveguides.

A large-scale physical model was designed and built to simulate slope failures on elements of soil, through which full-scale active waveguides were installed. A shear surface develops in each test and the sliding mass accelerates during failure, reaching velocities greater than $300 \mathrm{~mm} / \mathrm{h}$ and shear deformations of $50 \mathrm{~mm}$. Continuous measurements were obtained to examine the behaviour of active waveguides subjected to first-time slope failure dynamics (i.e. shear surface formation and accelerating deformation behaviour). This experiment has allowed the examination of full-scale active waveguides, which ensures the results from the study are applicable to active waveguide field installations in real slopes.

\section{APPARATUS DEVELOPMENT AND EXPERIMENTAL PROCEDURE \\ Design considerations}

Constructing a full-scale slope and inducing it to fail through pore-water pressure recharge (i.e. comparable to the Selborne experiment in Cooper et al. (1998)) or removal of support and stress relief through excavations of the toe (i.e. comparable to the Arseley experiment in Dixon et al. (2003)) can be used to examine the behaviour of active waveguides subjected to slope failure. However, it was preferable to develop a large-scale physical model as this would allow repeat testing, more variables could be controlled, and a greater understanding of the materials, the stress regime and the shear surface could be achieved. An important consideration in the design of the physical model was the stiffness moduli of the steel waveguide, which when present through a full-scale slope moving en masse are negligible; however, when installed through a physical model could cause significant resistance to deformation. The design of the apparatus needed to include sufficient strength and mass to represent a host landslide mass, and the method of load application needed to be sufficient to replicate typical accelerations and magnitudes of waveguide system deformation.

\section{Slope failure apparatus}

The apparatus was designed to allow full-scale active waveguides to be tested under conditions (e.g. shear mechanism, stresses, displacements and displacement rates) analogous to those they would experience in a slope undergoing first-time failure in the field. The apparatus was a bespoke large shear box (Figs 2 and 3), which comprised two concrete blocks, each with external dimensions $1.0 \times 0.7 \times 0.7 \mathrm{~m}$. The bottom box was fixed to a reinforced concrete floor to prevent movement and the top box was placed on top of the bottom box. Each box had an open column $(0 \cdot 3 \times 0.3 \mathrm{~m})$, which 


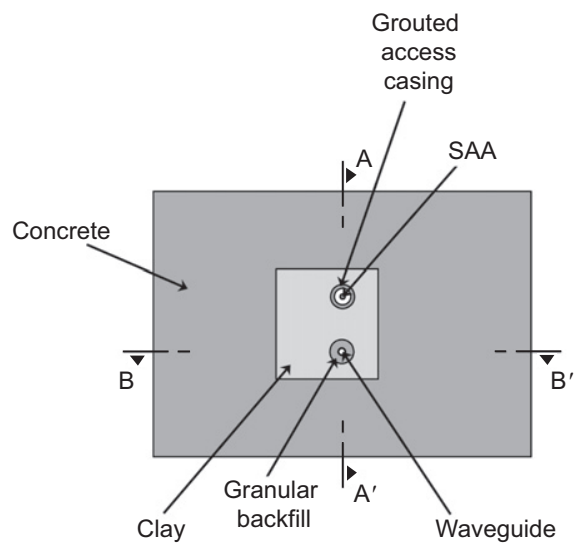

(a)

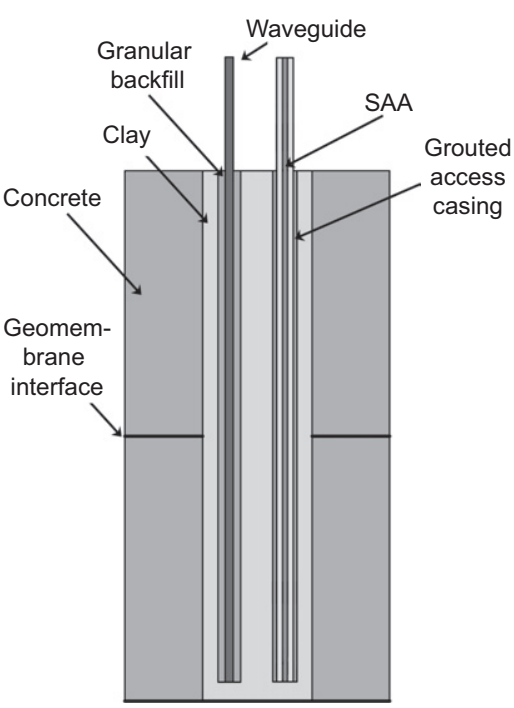

(b)

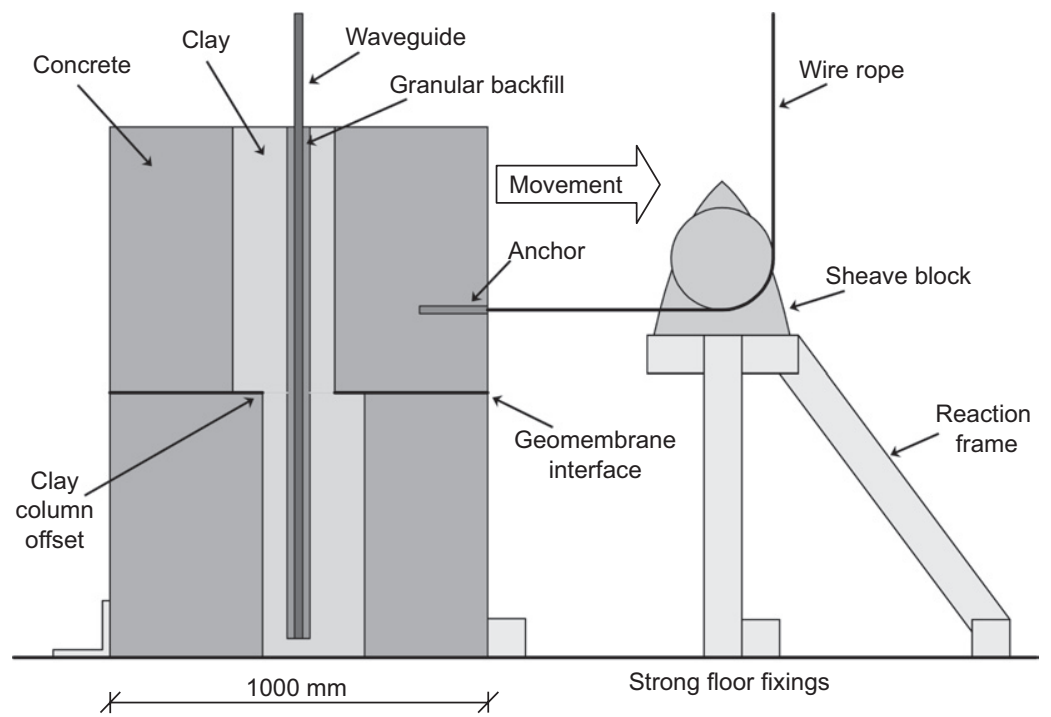

(c)

Fig. 2. Annotated illustration of the first-time slope failure experiment at the start of a test $(t=0)$. The top block is pulled horizontally to the right of the image by the wire rope during the test. The anchor, wire rope and pulley system are fastened centrally in the horizontal plane and are only shown on cross-section B-B' for illustrative purposes. The figure is to scale and has a dimension line for reference: (a) plan view; (b) cross-section $\mathbf{A}^{-\mathbf{A}^{\prime}}$; (c) cross-section $\mathbf{B}-\mathbf{B}^{\prime}$

was filled with soil to represent an element of the slope. A full-scale active waveguide was installed through this soil column. Although there are boundary effects at the soil column-box wall interface, the influence of these is assumed to be negligible at the active waveguide located within the soil column. The modelled system is therefore representative of a full-scale field active waveguide system when installed through a slope and intersecting an existing or potential shear surface(s).

The open column was offset at the shear box interface to allow for travel of the active waveguide through the soil column; a greater volume of soil is to the rear of the active waveguide in the top box relative to the volume of soil in front of it, and the opposite is the case in the bottom box. Smooth high-density polyethylene (HDPE) geomembrane $(2 \mathrm{~mm}$ thick) was fixed to the bottom of the top box and to the top of the bottom box to form a shear surface with low interface friction and allow for repeatable interface behaviour.

A pulley system (Figs 2 and 3 ) connects the top box to a hydraulically controlled loading ram, which was used to apply load and displacement to the shear box. The loading ram moves upwards, which pulls the wire rope around the sheave block, and moves the top box horizontally to induce shearing in the soil column. The wire rope was fixed in the front of the top box using an eye anchor and high-strength resin. The sheave block was fixed to a reaction frame at the appropriate elevation, which was fixed to the reinforced concrete floor. The entrance of the wire rope into the sheave block is $2 \mathrm{~cm}$ above the elevation of the resin anchor, to generate a small vertical component of force at the front of the top box during the experiments to reduce the frictional force at the shear box interface further.

\section{Soil slope element}

The soil slope element was processed Mercia Mudstone, comprising very silty clay of low plasticity (properties in Table 1). The clay was compacted with as-placed moisture contents in the range $16 \cdot 6-19.9 \%$ (Table 2; measured from at least six samples during each test set-up). This was 


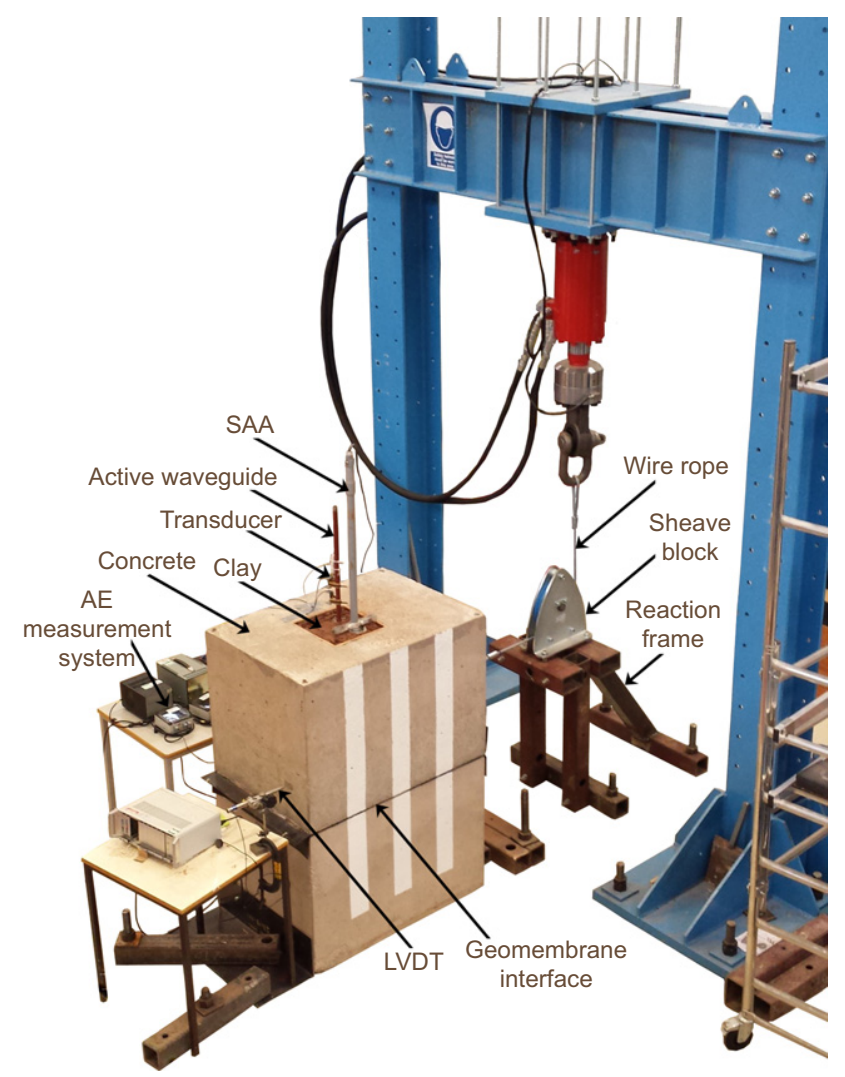

Fig. 3. Annotated photograph of the first-time failure experiment at the start of a test $(t=0)$

done to ensure the clay would fail plastically when sheared (i.e. a moisture content marginally wet of both the optimum moisture content and the plastic limit).

The clay was compacted in layers using vibration from a breaker-hammer with a square foot $(16 \times 16 \mathrm{~cm})$, which applied cycles of normal force to each layer. The clay was compacted in five layers in each box in test 1, each using 1 min of vibration. It became apparent during excavation of this test that this method of compaction left numerous voids, which became filled with bentonite-grout when the ShapeAccelArray (SAA) was installed (described in the next section entitled 'Instrumentation'). Therefore, the clay was compacted in ten layers in each box in test 2 , each using $2.5 \mathrm{~min}$ of vibration; this method resulted in successful compaction with no noticeable voids during excavation. The compaction effort required was less due to the material being less stiff in tests 3 and 4 (higher moisture content); 2 min of vibration were required for each layer in these tests. Test 5 used the same compaction effort as test 2 .

\section{Instrumentation}

Two $60 \mathrm{~mm}$ dia. holes were hand augered through the soil column (Figs 2 and 3). An active waveguide was installed in one of these holes, which comprised a $22 \mathrm{~mm}$ dia., $1.8 \mathrm{~m}$ long steel tube with $2 \mathrm{~mm}$ wall thickness (waveguides with the same geometry and properties are used in field installations). The annulus around the waveguide was backfilled with granular soil and compacted in $0 \cdot 2 \mathrm{~m}$ high lifts (the same materials and installation procedure are used in field installations). The waveguide protruded $0.4 \mathrm{~m}$ above the top box where the AE measurement system was coupled. A SAA with $0.2 \mathrm{~m}$ gauge lengths was installed in the second hole. The SAA comprises a string of micro-electromechanical systems (MEMS) sensors, which measure threedimensional displacements continuously, and the SAA has an accuracy of $+/-1.5 \mathrm{~mm}$ over a length of $30 \mathrm{~m}$ (Abdoun et al., 2013). The bottom SAA MEMS sensor was positioned at a height of $0.1 \mathrm{~m}$ above the base of the soil column. The SAA was installed inside unplasticised polyvinyl chloride (UPVC) access casing and the annulus around the casing was backfilled with bentonite-grout (standard installation procedure). Relative proportions of the bentonite-grout mix were $1,0 \cdot 17$ and $0 \cdot 07$ for water, cement and bentonite, respectively. The bentonite-grout was left to harden around the SAA for 4 days prior to the start of each test. The SAA recorded deformation at 30-s intervals. A linear variable differential transducer (LVDT) (with accuracy greater than $+/-0.5 \%$ ) was installed at the rear of the top box to measure horizontal movement of the block, and the load applied to the ram was measured using a load cell (with accuracy greater than $+/-0 \cdot 2 \%)$ throughout the experiments.

\section{AE measurement system}

A field-viable AE measurement system was used in this study. This system was used to ensure the results obtained are relevant to field monitoring applications. The system is described as 'field-viable' because it includes functionality to remove low-frequency background noise (e.g. generated by construction activity and traffic) and it has low power requirements, which makes continuous monitoring for long durations in the field environment possible. A piezoelectric transducer was employed to convert the mechanical AE to an electrical signal. The transducer was a R3alpha (Physical Acoustics Corporation) with a $30 \mathrm{kHz}$ resonant frequency and this was selected to provide sensitivity over the monitored frequency range of $20-30 \mathrm{kHz}$. The transducer is coupled to the outer wall of the waveguide with a small layer of silicone gel, and held in position using the compressive contact provided by an elastic band and cable tie. A band pass filter attenuated signals outside the $20-30 \mathrm{kHz}$ range to eliminate low-frequency background noise $(<20 \mathrm{kHz})$ and to keep the monitored range consistent with that used in field trials (Smith et al., 2014a, 2014b; Smith, 2015; Dixon et al., 2015a, 2015b). Amplification of $70 \mathrm{~dB}$ was used to improve the signal-to-noise ratio. Such field instrumentation should employ relatively simple processing to minimise power and storage capacity requirements. Therefore, ring-down counts (RDCs) per unit time were recorded and these are the units of measured $\mathrm{AE}$ rates. AE rates (RDC rates) are the number of times the AE signal amplitude crosses a programmable threshold level within a predefined time period, and these were recorded using a comparator. A voltage threshold level of $0.25 \mathrm{~V}$ was used with a monitoring interval of $5 \mathrm{~s}$; these RDC per $5 \mathrm{~s}$ measurements were converted to more conventional equivalent RDC per hour values.

Table 1. Clay properties

\begin{tabular}{l|c|c|c|c|c|c}
\hline Name & $\begin{array}{c}\text { Plastic } \\
\text { limit: } \%\end{array}$ & $\begin{array}{c}\text { Liquid } \\
\text { limit: } \%\end{array}$ & $\begin{array}{c}\text { Plasticity } \\
\text { index: } \%\end{array}$ & $\begin{array}{c}\text { Particle density: } \\
\mathrm{Mg} / \mathrm{m}^{3}\end{array}$ & $\begin{array}{c}\text { Optimum moisture } \\
\text { content: } \%\end{array}$ & $\begin{array}{c}\text { Maximum dry } \\
\text { density: } \mathrm{Mg} / \mathrm{m}^{3}\end{array}$ \\
\hline Clay & $14 \cdot 8$ & $30 \cdot 0$ & $15 \cdot 2$ & $2 \cdot 54$ & $15 \cdot 5$ & $1 \cdot 86$ \\
\hline
\end{tabular}


Table 2. Test details

\begin{tabular}{l|l|c}
\hline $\begin{array}{l}\text { Test } \\
\text { number }\end{array}$ & Backfill & $\begin{array}{c}\text { Clay moisture } \\
\text { content: } \%\end{array}$ \\
\hline 1 & Limestone gravel (LSG) & $18 \cdot 6$ \\
2 & Limestone gravel (LSG) & $17 \cdot 4$ \\
3 & Limestone gravel (LSG) & $19 \cdot 9$ \\
4 & Leighton Buzzard sand (LBS) & $18 \cdot 8$ \\
5 & Granite gravel (GG) & $16 \cdot 6$ \\
\hline
\end{tabular}

Active waveguide backfills

Three granular waveguide backfill materials were used to investigate the influence of their properties on the AE rates generated from the active waveguide system. The backfill materials were selected because they are typical aggregates and non-specialised materials, and using materials that are easy to procure facilitates their widespread use. The backfills tested also provided a range of particle sizes to investigate. Three tests were performed, using the same backfill material in order to evaluate repeatability. Subsequently, two further experiments were performed with other materials. The materials were limestone gravel (LSG), Leighton Buzzard sand (LBS) and granite gravel (GG). Photographs of the granular soils and their particle size distributions are shown in Fig. 4.

Table 2 details which backfills were installed in which test and Table 3 compares their particle size, particle shape and packing properties. Particle shape parameters, namely roundness (i.e. angularity), sphericity (i.e. ellipticity or platiness) and regularity, were determined using twodimensional images of the particles. Roundness is quantified as the average radius of curvature of particle surface features relative to the radius of the maximum sphere that can be inscribed in the particle. Sphericity is quantified as the radius ratio between the largest inscribed and the smallest circumscribing sphere. Regularity is the mean of roundness and sphericity (Krumbein \& Sloss, 1963; Cho et al., 2006; Cavarretta et al., 2010; Zheng \& Hryciw, 2015).

\section{Test procedure}

All tests were displacement rate controlled, and displacement-time functions (Table 4) were designed to represent the deformation behaviour that slopes experience as they lose strength and accelerate during progressive failure. The slowest rate of movement was the lowest allowable by the loading machine. The duration of the first two stages of the experiment was progressively increased between test 1 and test 3 to apply the lowest rates of deformation for greater magnitudes of deformation. The same function was applied in tests 3 to 5 .

The authors designed the experiment to ensure the sliding mass travelled $50 \mathrm{~mm}$ in each test, which required a set-up protocol to minimise extension of the wire rope during the tests. Before each test, a constant movement rate of $0.1 \mathrm{~mm} / \mathrm{min}$ was applied. Movement was ceased at the point at which the LVDT detected movement. After this

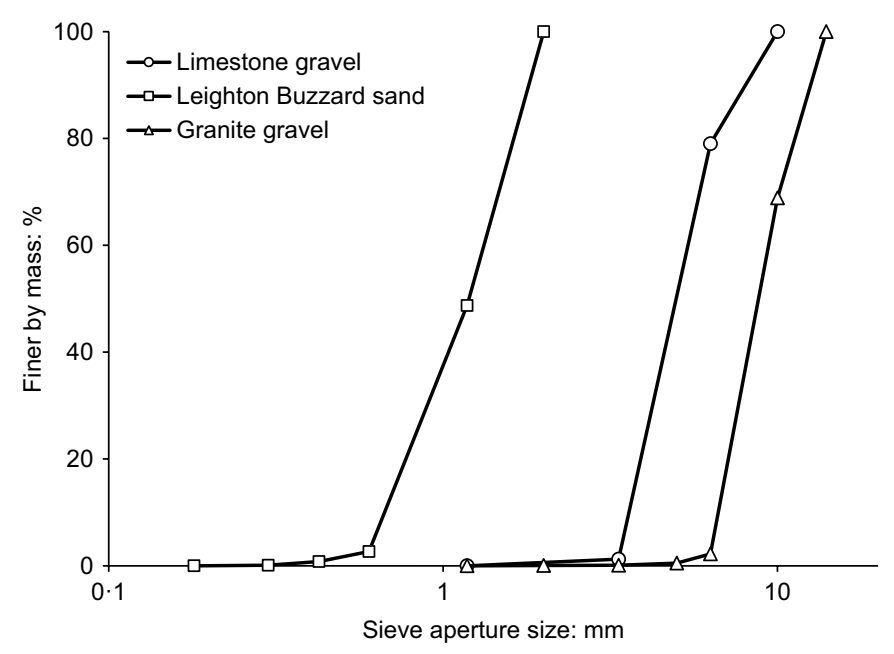

(a)

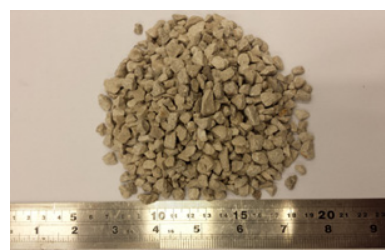

(b)

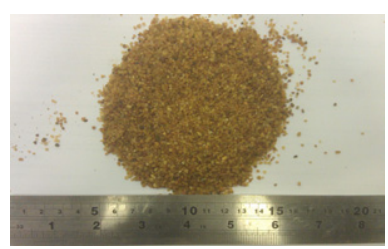

(c)

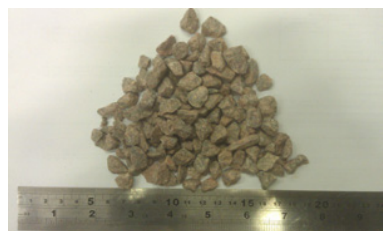

(d)

Fig. 4. (a) Particle size distributions of the granular backfill materials, and photographs of the backfill materials: (b) LSG; (c) LBS; (d) GG

Table 3. Particle size, particle shape and packing properties of the granular backfills

\begin{tabular}{|c|c|c|c|c|c|c|c|c|}
\hline \multirow[t]{2}{*}{ Description } & \multicolumn{2}{|c|}{ Particle size } & \multicolumn{3}{|c|}{ Particle shape } & \multicolumn{3}{|c|}{ Packing } \\
\hline & $\begin{array}{l}\text { Size range: } \\
\mathrm{mm}\end{array}$ & $\begin{array}{c}\text { Coefficient } \\
\text { of uniformity }\end{array}$ & Roundness & Sphericity & Regularity & $\begin{array}{c}\text { Particle } \\
\text { density: } \mathrm{Mg} / \mathrm{m}^{3}\end{array}$ & $\begin{array}{l}\text { Dry density: } \\
\mathrm{Mg} / \mathrm{m}^{3}\end{array}$ & $\begin{array}{l}\text { Void } \\
\text { ratio }\end{array}$ \\
\hline Limestone gravel (LSG) & $3 \cdot 0-8 \cdot 0$ & $1 \cdot 51$ & $0 \cdot 3-0 \cdot 5$ & $0 \cdot 5-0 \cdot 8$ & $0 \cdot 4-0 \cdot 6$ & $2 \cdot 64$ & $1 \cdot 53$ & $0 \cdot 730$ \\
\hline Leighton Buzzard sand (LBS) & $0 \cdot 3-1 \cdot 8$ & 1.93 & $0 \cdot 2-0 \cdot 5$ & $0 \cdot 4-0 \cdot 8$ & $0 \cdot 3-0 \cdot 6$ & $2 \cdot 67$ & $1 \cdot 70$ & $0 \cdot 567$ \\
\hline Granite gravel (GG) & $5 \cdot 0-12 \cdot 0$ & $1 \cdot 41$ & $0 \cdot 1-0 \cdot 3$ & $0 \cdot 3-0 \cdot 8$ & $0 \cdot 2-0 \cdot 6$ & $2 \cdot 68$ & $1 \cdot 58$ & $0 \cdot 699$ \\
\hline
\end{tabular}


Table 4. Displacement rate-controlled function applied in tests 3, 4 and 5. Note that stages 1 and 2 were applied for shorter durations in tests 1 and 2

\begin{tabular}{|c|c|c|c|c|c|}
\hline \multirow[t]{2}{*}{ Stage } & \multicolumn{2}{|c|}{ Applied displacement rate to wire rope } & \multirow[t]{2}{*}{ Duration: $\min$} & \multirow[t]{2}{*}{ Cumulative time: $\min$} & \multirow[t]{2}{*}{ Cumulative displacement: $\mathrm{mm}$} \\
\hline & $\mathrm{mm} / \mathrm{min}$ & $\mathrm{mm} / \mathrm{h}$ & & & \\
\hline $\begin{array}{l}1^{*} \\
2 \dagger \\
3 \\
4 \\
5 \\
6 \\
7 \\
8\end{array}$ & $\begin{array}{l}0 \cdot 06 \\
0 \cdot 12 \\
0 \cdot 25 \\
0 \cdot 5 \\
1 \\
2 \\
4 \\
6\end{array}$ & $\begin{array}{c}3 \cdot 6 \\
7 \cdot 2 \\
15 \\
30 \\
60 \\
120 \\
240 \\
360\end{array}$ & $\begin{array}{r}50 \\
25 \\
10 \\
8 \\
5 \\
4 \\
3 \\
3\end{array}$ & $\begin{array}{r}0 \\
50 \\
75 \\
87 \\
95 \\
100 \\
104 \\
107 \\
110\end{array}$ & $\begin{array}{r}0 \\
3 \\
6 \\
9 \\
13 \\
18 \\
26 \\
38 \\
56\end{array}$ \\
\hline
\end{tabular}

*Stage 1 lasted for $15 \mathrm{~min}$ in test 1 and $35 \mathrm{~min}$ in test 2 .

† Stage 2 lasted for $10 \mathrm{~min}$ in test 1 and $20 \mathrm{~min}$ in test 2 .

initial box movement, the test was in the start position and the displacement-time function (Table 4) was then applied to the top box. The LVDT and SAA measured the actual movement of the top box and the soil column, respectively. The soil column was excavated at the end of each test and the instruments were removed, prior to setting up the subsequent test.

\section{RESULTS AND ANALYSIS}

\section{Deformation and load behaviour}

Figure 5 shows displacement plotted against time measurements recorded during test 3 by the loading ram, the LVDT, and the SAA MEMS sensor located above the shear surface at a height of $0.9 \mathrm{~m}$ (resultant horizontal deformation); comparable behaviour was measured in each test. All SAA time series measurements presented are taken from this MEMS sensor, and they are the resultant of the horizontal deformation. Ram deformation of $<3 \mathrm{~mm}$ was taken up by extension in the wire rope throughout the test, which is evident from the difference between the ram position and LVDT displacement. A difference of $<1 \mathrm{~mm}$ between the LVDT measured block movement and the SAA measured deformation developed during stages 1 and 2, prior to shear surface formation in the clay.

Figure 6 shows the height plotted against resultant horizontal SAA deformation measurements at the end of each stage during test 3 (comparable behaviour was measured in each test). Height is relative to the base of the bottom box. The interface between the two blocks is at a height of $0.7 \mathrm{~m}$, which also corresponds to the location of a MEMS sensor. The apparent shear zone is $0.4 \mathrm{~m}$ thick, $0.2 \mathrm{~m}$ above and below the interface; however, this is because the adjacent MEMS sensors are $0.2 \mathrm{~m}$ away. The real shear zone was significantly thinner $(<2 \mathrm{~cm})$ at a height of $0.7 \mathrm{~m}$; this was confirmed by visual inspection during forensic dismantling of each test.

Shear surface formation began in stage 2; this is clear from the measurements in Fig. 6, which show the SAA rotating about its base only during stage 1 (i.e. no relative shear movement between MEMS sensors is identifiable). The load plotted against deformation measurements shown in Fig. 7 support this as elastic deformation occurs until stage 2 in each test, at which point a transition to plastic deformation occurs (i.e. the shear surface forms). This transition is smooth with no drop in load in tests 1,2 and 5, whereas in tests 3 and 4 a drop in load is identifiable.

The differences in load-deformation measurements were principally governed by the composition of the clay column, for example: tests 1 to 3 used the same active waveguide

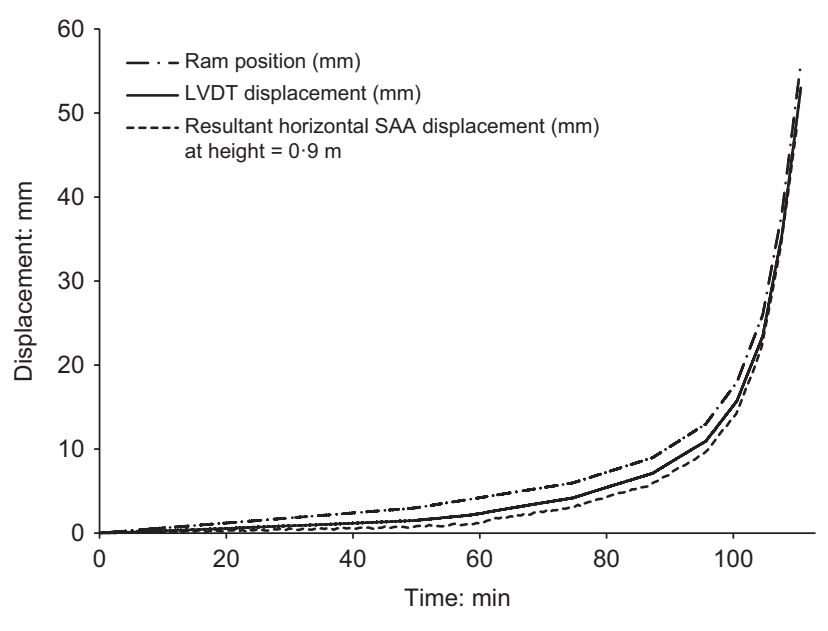

Fig. 5. Ram position, LVDT displacement and resultant horizontal SAA displacement plotted against time (test 3)

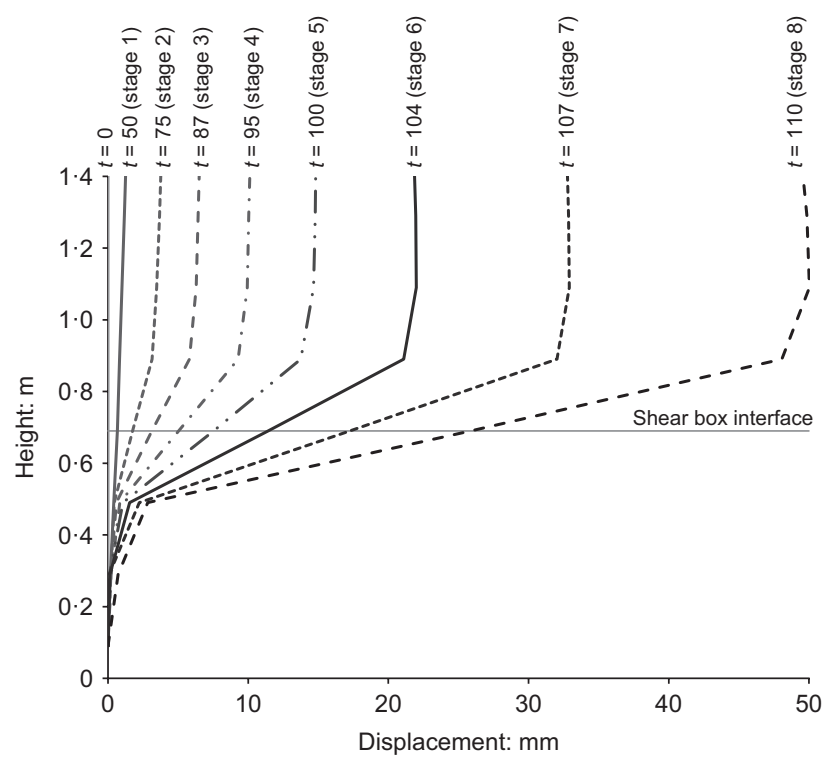

Fig. 6. Height above the base of the shear box plotted against SAA measured resultant horizontal deformation from test 3 for the end of each stage at time $t(\mathrm{~min})$

backfill but experienced noticeably different behaviour. The clay installed in tests 3 and 4 had comparable stiffness (moisture content and compaction effort) and experienced comparable behaviour. This was also the case for tests 2 and 5 . 


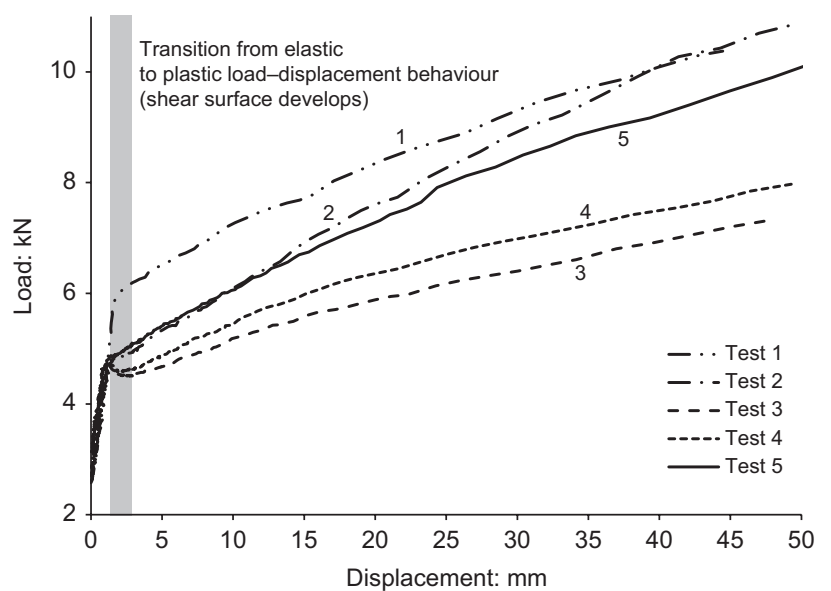

Fig. 7. Load plotted against displacement data for each test. Note that displacement is taken from the SAA MEMS sensor immediately above the shear surface (at a height of $0.9 \mathrm{~m}$ )
Test 1 experienced different behaviour: the voids in the clay in test 1 became filled with bentonite-grout that infiltrated when the SAA was installed, increasing the strength of the clay column.

The SAA deformation progressively increased below the shear surface as the SAA was pulled horizontally through the bentonite-grout and clay in the bottom box, resulting in behaviour analogous to a laterally loaded flexible (high slenderness ratio) pile. This mechanism is likely to have begun earlier, in response to smaller magnitudes of movement, in the active waveguide due to its significantly greater stiffness.

\section{$A E$ and deformation behaviour}

Tests 1 to 3 (repeatability). Figure 8 presents time series measurements from test 3 . The cumulative RDC measurements are proportional to the SAA measured displacement, and the AE rate measurements are proportional to the SAA measured velocity. Velocity smoothing was done using 2-min moving average values, by calculating the average of the

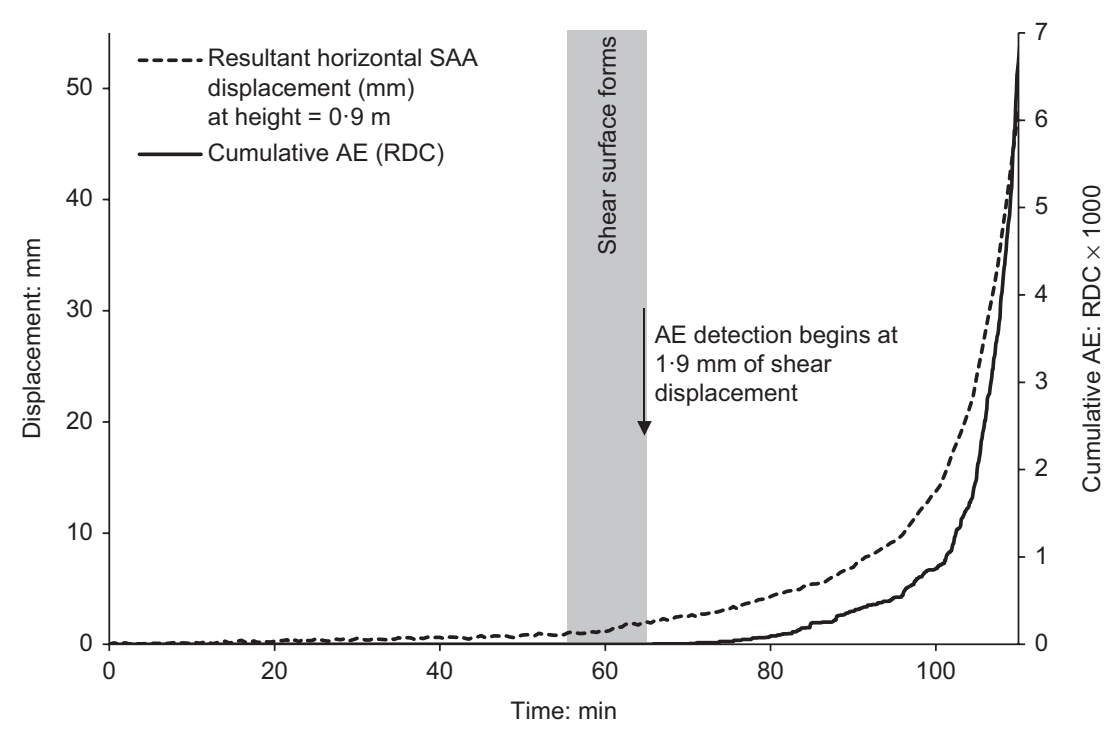

(a)

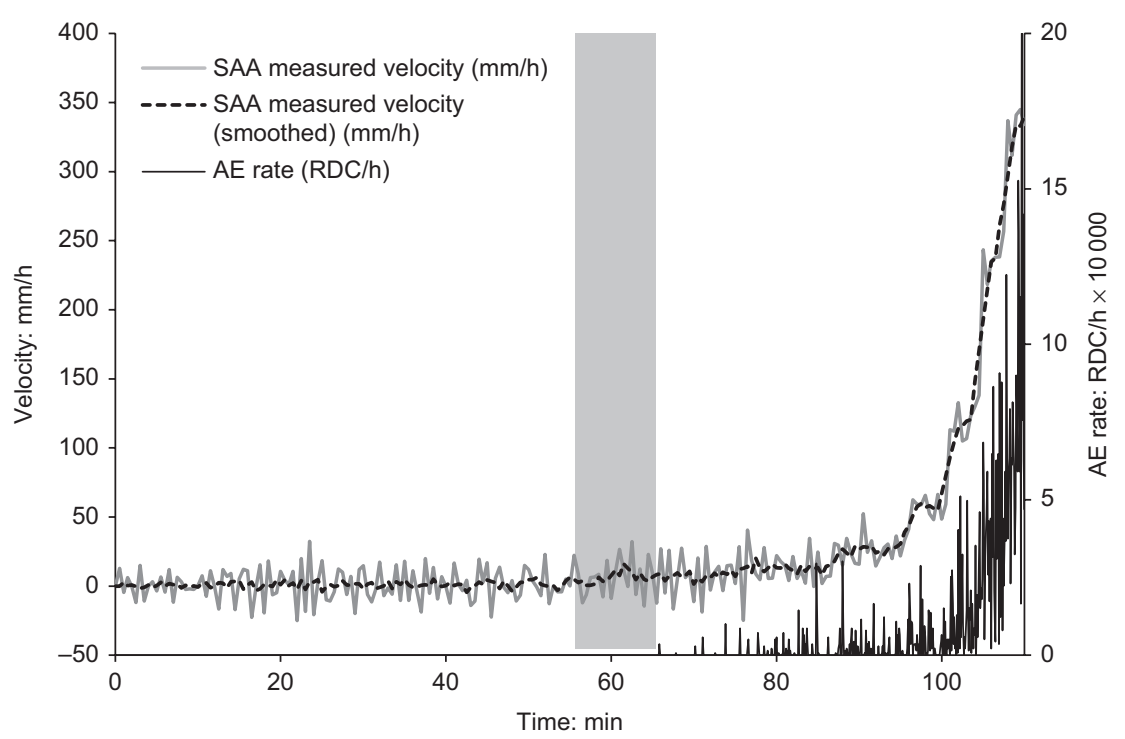

(b)

Fig. 8. Time series of measurements from test 3: (a) displacement and cumulative RDC plotted against time; (b) SAA velocity and AE rate plotted against time. AE rates presented are significantly greater than the cumulative RDC because they have been converted to equivalent RDC/h values 


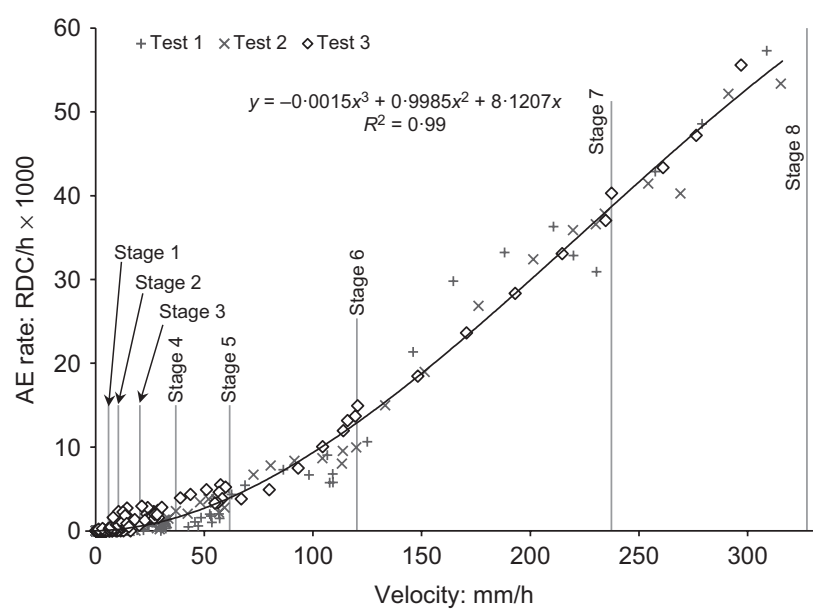

Fig. 9. Comparison of $\mathrm{AE}$ rate-velocity relationships determined from tests 1, 2 and 3. Data points are 2-min moving average values. The annotated stages show the end of each displacement rate stage

velocity during the minute preceding and minute succeeding each measurement. The recorded velocity briefly reduced at the end of each stage before entering the subsequent stage; this same behaviour is identifiable in the AE rate measurements. AE detection began after $1.9 \mathrm{~mm}$ of shear deformation in this test, as the shear surface was forming (described in the previous section entitled 'Deformation and load behaviour').

Figure 9 shows AE rate-SAA measured velocity relationships from tests 1 to 3 . The relationships from the three tests overlap, demonstrating that active waveguide-generated AE is repeatable, and that empirical $\mathrm{AE}$ rate-velocity relationships can be defined. A third-order polynomial, fitted using regression through all three data sets, displays strong correlation ( $R^{2}$ value of 0.99$)$. A transition in behaviour occurs during stages 5 and 6 , causing the gradient of this relationship to increase.

Granular shearing takes place within the active waveguide at the shear surface as the sliding mass begins to move. The backfill deforms around the waveguide with further displacement, as the waveguide resists shear and bending. Analogous to a laterally loaded pile, reactions from the host soil cause the pressures along the active waveguide to increase. Reactions from both the host soil and the waveguide cause the confining pressures in the backfill to increase. Both the volume of backfill being deformed and the confining pressures in the backfill increase with displacement. This behaviour causes the AE rate-velocity relationship gradient to increase (e.g. Smith \& Dixon (2015) introduced the influence of confining pressures on this relationship).

Tests 1 to 5 (backfill comparisons). Figure 10 presents AE rate and velocity time series measurements from tests 3 to 5 (note the different AE rate axis scales used). AE rates generated from each active waveguide backfill are proportional to the applied velocity throughout each of the time series. Both the LBS and GG backfills generated significantly greater AE than the LSG, by more than an order of magnitude. AE was detected earliest in test 5 with GG backfill, after $0.84 \mathrm{~mm}$ of shear deformation. AE rates detected in test 5 while the shear surface was forming were significantly greater than those detected in test 3 using LSG. Fig. 11 shows the first $80 \mathrm{~min}$ of the time series in test 5, which highlights the significant levels of AE detected after this small magnitude of shear deformation. Annotation in Figs 8, 10 and 11 shows the magnitude of shear deformation (measured by the SAA) experienced prior to AE detection, which was $1.9 \mathrm{~mm}$ in test $3,0.96 \mathrm{~mm}$ in test 4 and $0.84 \mathrm{~mm}$ in test 5 . The shear displacement rate measured by the SAA at the time of AE detection was $3.8 \mathrm{~mm} / \mathrm{h}$ in test $3,1.3 \mathrm{~mm} / \mathrm{h}$ in test 4 and $0.6 \mathrm{~mm} / \mathrm{h}$ in test 5 .

Figure 12 shows the AE rate-SAA measured velocity relationships for each active waveguide type. Each relationship demonstrates strong positive correlation. The relationship defined for the LSG (Fig. 12(a)) amalgamates results from tests 1 to 3 . The purpose of the system is to detect and quantify order of magnitude changes in slope displacement rates, for example, to alert the user that the slope has accelerated from a 'slow' to a 'moderate' rate of displacement (e.g. Fig. 1), and which would then be used in risk management. Variability in the data in Fig. 12 is negligible in comparison to changes in orders of magnitude.

A systematic statistical approach to curve fitting was performed, which resulted in these equations (third-order polynomials) achieving the greatest statistical match to the measured relationships over the range of values examined. These curves are used for three purposes: to describe the data and the measured relationships between the two variables (i.e. $\mathrm{AE}$ rates generated in response to applied displacement rates) for each active waveguide backfilled with different material; to facilitate understanding of what behaviour is physically causing the data to create the relationships they do; and to define empirical relationships that allow users to quantify displacement rates from measured AE rates.

The third-order polynomials have been used successfully to define empirical AE rate-velocity relationships for the active waveguides, resulting in $R^{2}$ values of 0.99 in each case. The gradient in each AE rate-velocity relationship increases, due to the mechanisms described in the section entitled 'Tests 1 to 3 (repeatability)'. The rate of this gradient increase is greater with the LBS backfill than with the other two materials. This is because more particle-particle contacts exist within backfill that has smaller particles, and the number of particle-particle interactions increases more rapidly as the volume of backfill deforming around the waveguide increases.

The insets in Fig. 12 show each of the relationships up to an applied velocity of $100 \mathrm{~mm} / \mathrm{h}$, which can usefully be approximated using linear relationships. The correlation in each linear relationship is strong, with $R^{2}$ values ranging from 0.78 to 0.96 . This supports results obtained from a field trial by Smith et al. (2014a) who found a linear AE rate-velocity relationship for velocities $<0.3 \mathrm{~mm} / \mathrm{h}$ from reactivated slope movements.

Figure 13 compares the AE rates measured from each active waveguide backfill material in response to the full range of applied velocities. The curves show the ratio between the AE rates measured from the GG to both the LSG and LBS. Comparisons are made relative to the GG because it consistently generated the greatest $\mathrm{AE}$ rates, of between 180 and 1960 times greater than from the LSG; the greatest difference was at the lowest velocities $(<50 \mathrm{~mm} / \mathrm{h})$ because AE detection began later when backfilling with the LSG. The GG generated between $2 \cdot 1$ and 6 times greater AE rates than the LBS.

Although these results are specific to the frequency range of $20-30 \mathrm{kHz}$ and each backfill material could have produced high-energy AE outside this frequency range (e.g. Koerner et al. (1981) and Michlmayr \& Or (2014) show that deforming soils can generate $\mathrm{AE}$ with a wide range of frequencies, from $\mathrm{Hz}$ to $100 \mathrm{~s}$ of $\mathrm{kHz}$, and soils with different characteristics can have different dominant frequencies), they demonstrate that the particle size, particle shape and packing characteristics of granular backfills can significantly 


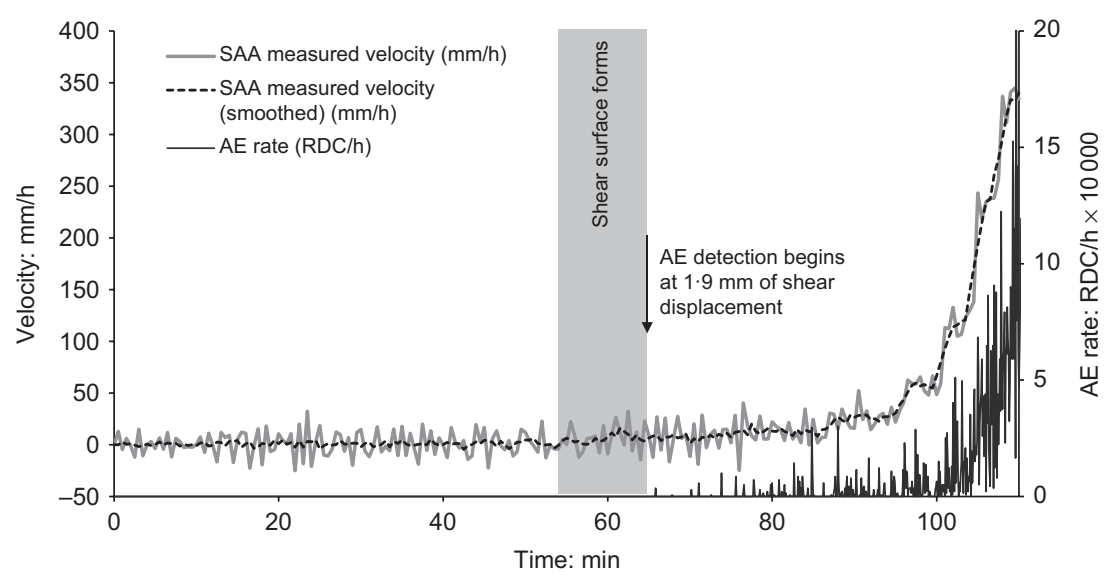

(a)

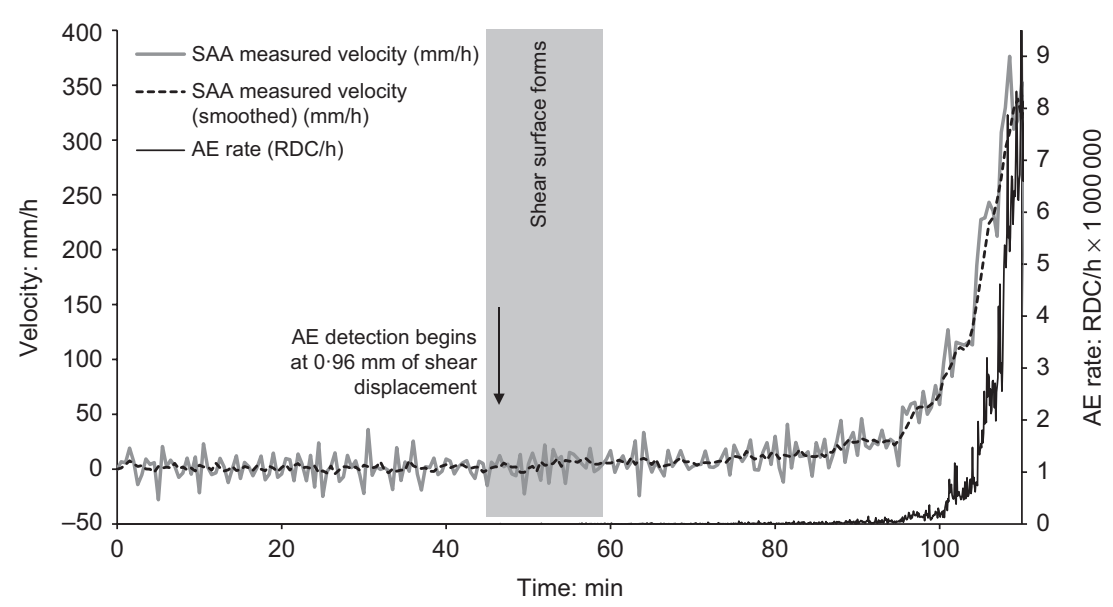

(b)

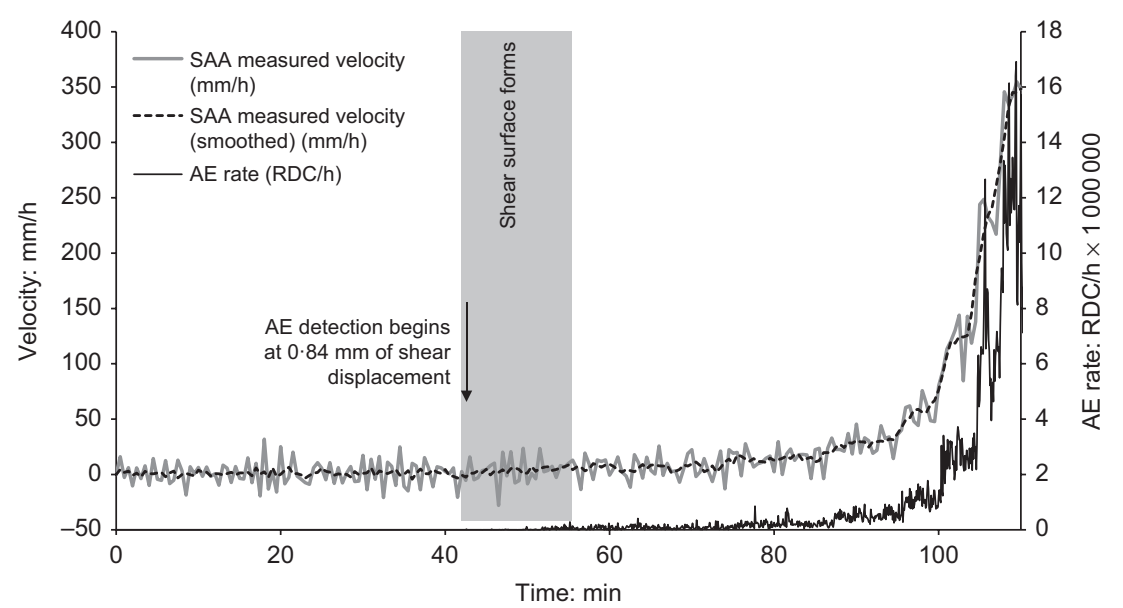

(c)

Fig. 10. AE rate and velocity plotted against time from tests 3, 4 and 5: (a) LSG; (b) LBS; and (c) GG. Note the different AE rate axis scales used

influence the AE they produce. The GG had the largest particles with the greatest angularity (Table 3). The LBS had the greatest coefficient of uniformity and lowest void ratio (densest packing). The LSG had the highest void ratio and its particles had the lowest angularity.

\section{DISCUSSION}

A series of experiments have been performed to subject full-scale active waveguides to the conditions they would experience when installed through a slope undergoing first-time failure. The conditions of the failure process were informed by the Selborne cutting stability experiment (Cooper et al., 1998). A shear surface forms in each test and the sliding mass gradually accelerates from displacement rates $<0.5 \mathrm{~mm} / \mathrm{h}$ to rates $>300 \mathrm{~mm} / \mathrm{h}$. Measured AE rates have been shown to increase proportionally with the applied rates of shear displacement, in each test, with each backfill. This demonstrates that the AE monitoring approach can be used to quantify slope displacement rates from measured $\mathrm{AE}$ rates using calibration $\mathrm{AE}$ ratevelocity relationships. This information can provide early detection of accelerating deformation behaviour that slopes experience during failure. 


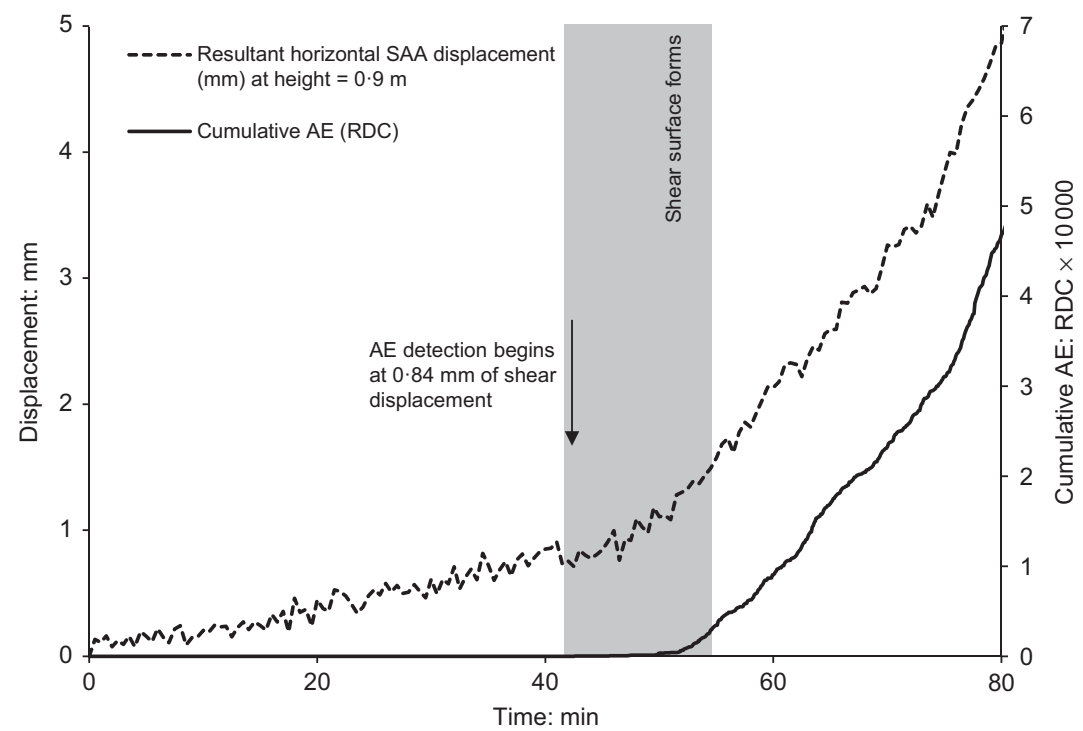

(a)

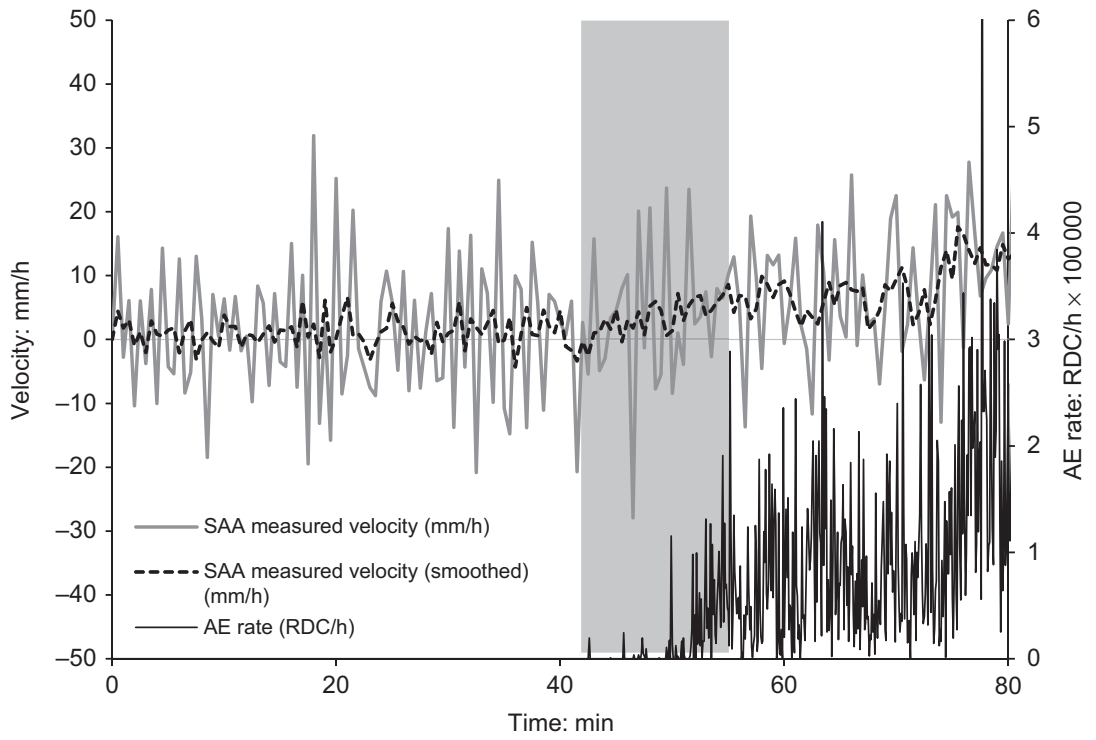

(b)

Fig. 11. Time series of measurements from the first 80 min of test 5: (a) displacement and cumulative RDC plotted against time; (b) velocity and $\mathrm{AE}$ rate plotted against time. AE rates presented are significantly greater than the cumulative RDC because they have been converted to equivalent RDC/h values

The majority of the measurements in this study were made at displacement rates above $0.5 \mathrm{~mm} / \mathrm{h}$; however, previous research through field trials reported by the authors in Smith et al. (2014a) demonstrates that the AE monitoring technique can measure slope displacement rates below $0.3 \mathrm{~mm} / \mathrm{h}$ once a continuous shear surface has formed (example AE rate-velocity measurements from this field study are shown in Fig. 14). The mechanisms of shear surface formation in the tests reported here prevented the examination of 'extremely slow' displacement rates. This is because the magnitude and rate of displacements are linked; more than $0.7 \mathrm{~mm}$ of deformation was required to overcome the apparatus compliance and begin to form the shear surface in each test, and it would be impractical to apply 'extremely slow' displacement rates during this test phase because it would take days, even weeks, for the shear surface to form.

Shearing was induced in the active waveguide when the shear surface began to form, initiating particle-particle/particle-waveguide interactions, which generated AE. AE detection began at the onset of shear surface formation when using waveguides backfilled with the GG and LBS; however, when using waveguides backfilled with the LSG, AE detection began after the majority of the shear surface had already formed. This is a significant finding because knowledge of when a shear surface is forming within a slope can contribute to improving slope risk management.

Empirical AE rate-slope velocity relationships were derived for three different active waveguide backfill types, which allow slope displacement rates to be quantified from measured $\mathrm{AE}$ rates when using these instruments and monitoring in the $20-30 \mathrm{kHz}$ range. These empirical relationships allow Class A (Lambe, 1973) a priori predictions to be made about how the active waveguide will respond (i.e. the $\mathrm{AE}$ rates it will generate) to a range of slope movement rates as first-time failure develops. This has been demonstrated by performing multiple tests with the same active waveguide backfill (LSG), which confirms that these AE rate-displacement rate relationships are repeatable.

Figure 15 shows how these relationships can be used to derive $\mathrm{AE}$ rate warning trigger levels, based on slope 


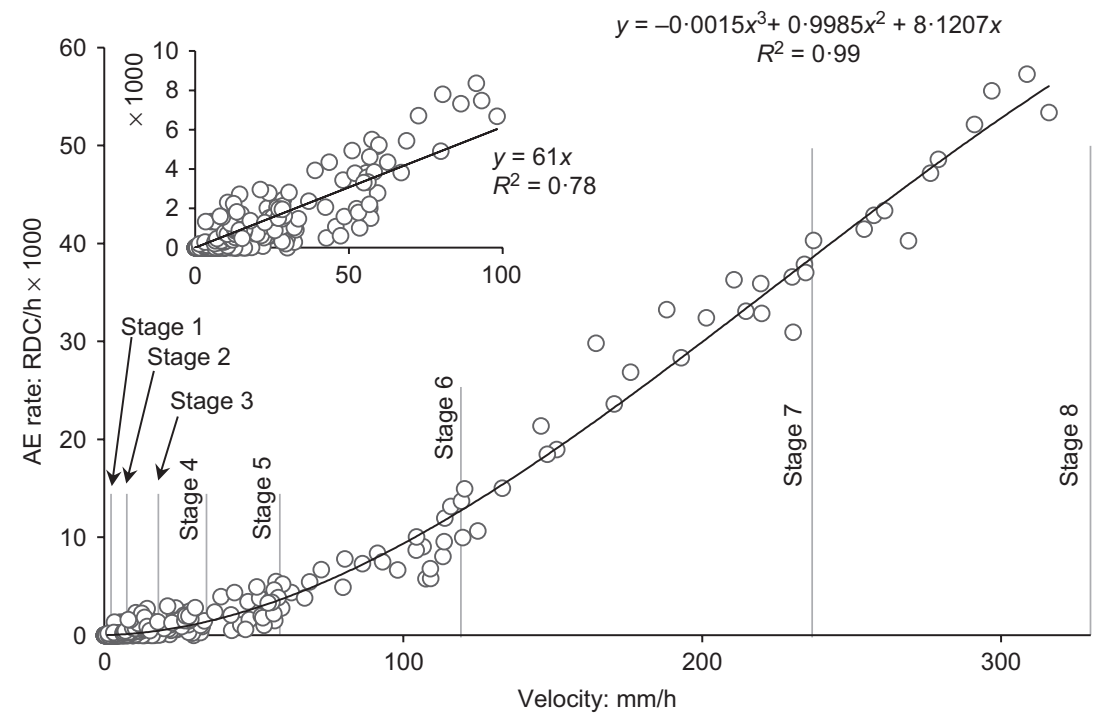

(a)

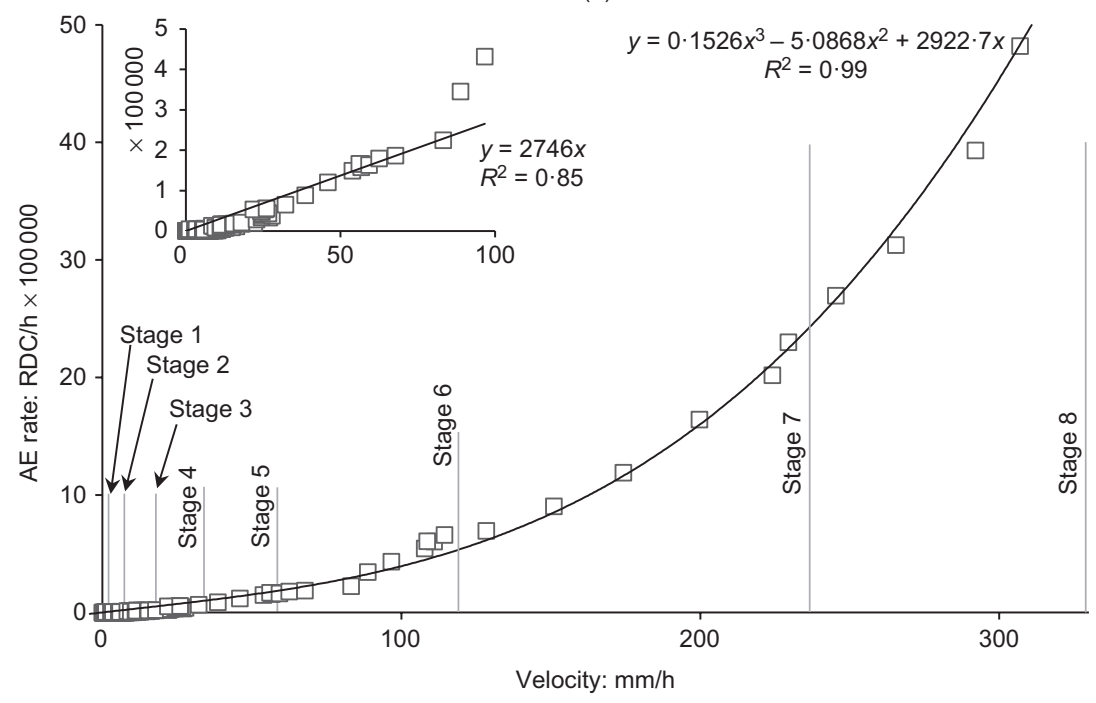

(b)

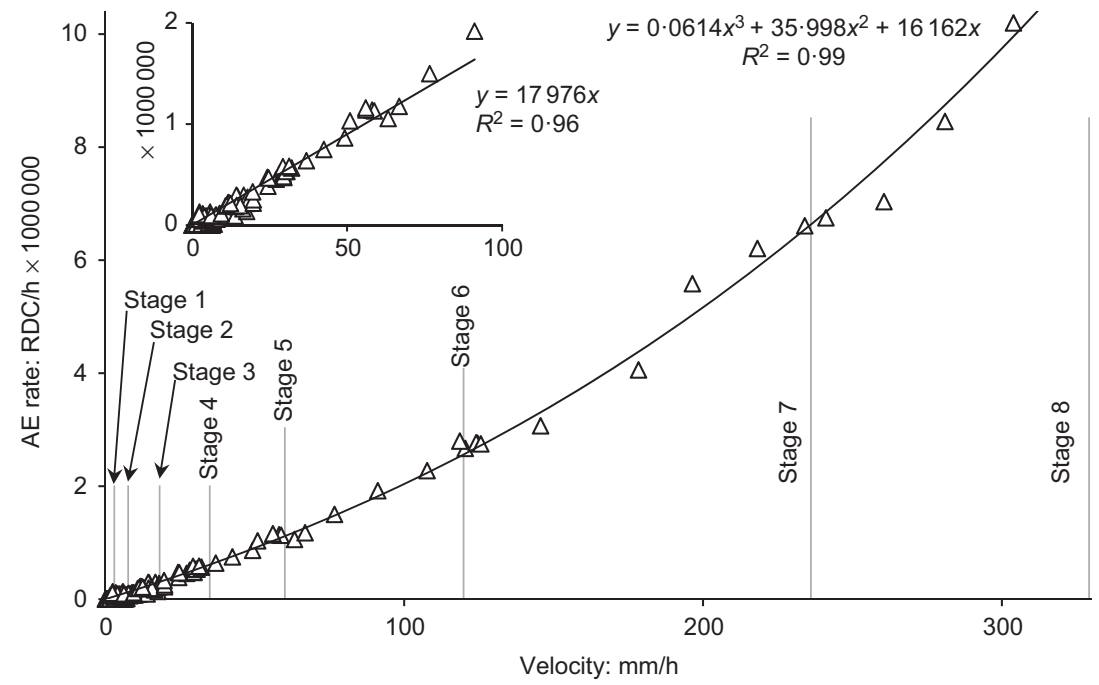

(c)

Fig. 12. Comparison of AE rate-velocity relationships determined from experiments on each backfill type: (a) LSG; (b) LBS; (c) GG. The insets show the AE rate-velocity relationships up to a velocity of $100 \mathrm{~mm} / \mathrm{h}$. Data points are 2 -min moving average values. The annotated stages show the end of each stage 


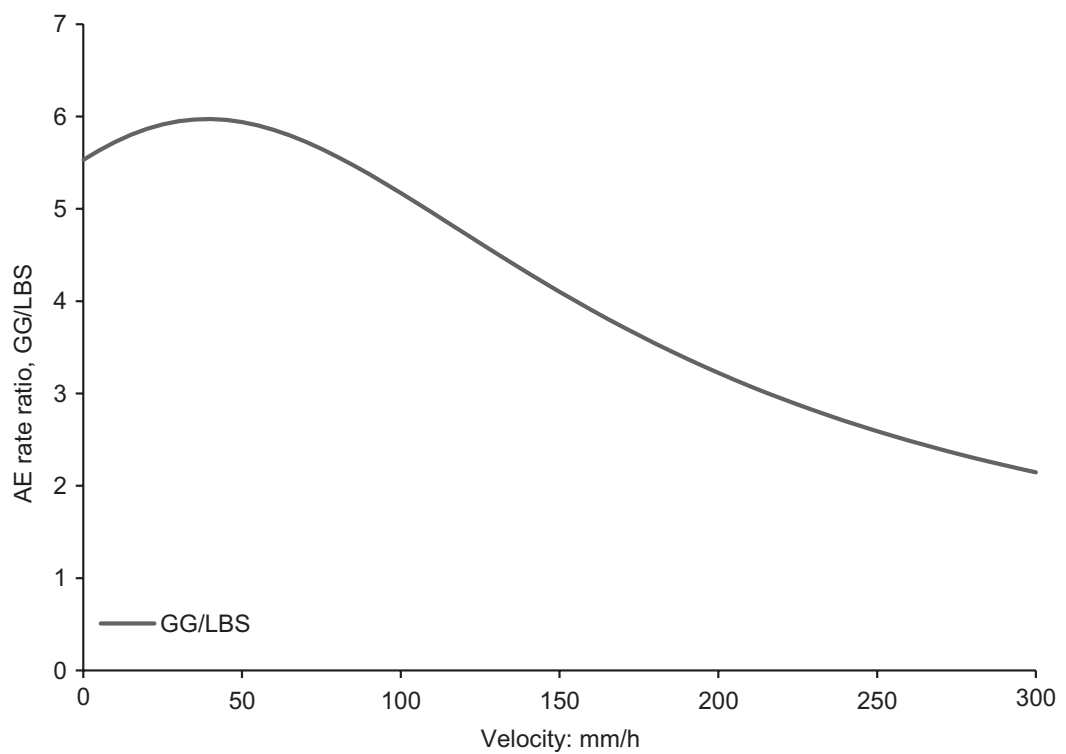

(a)

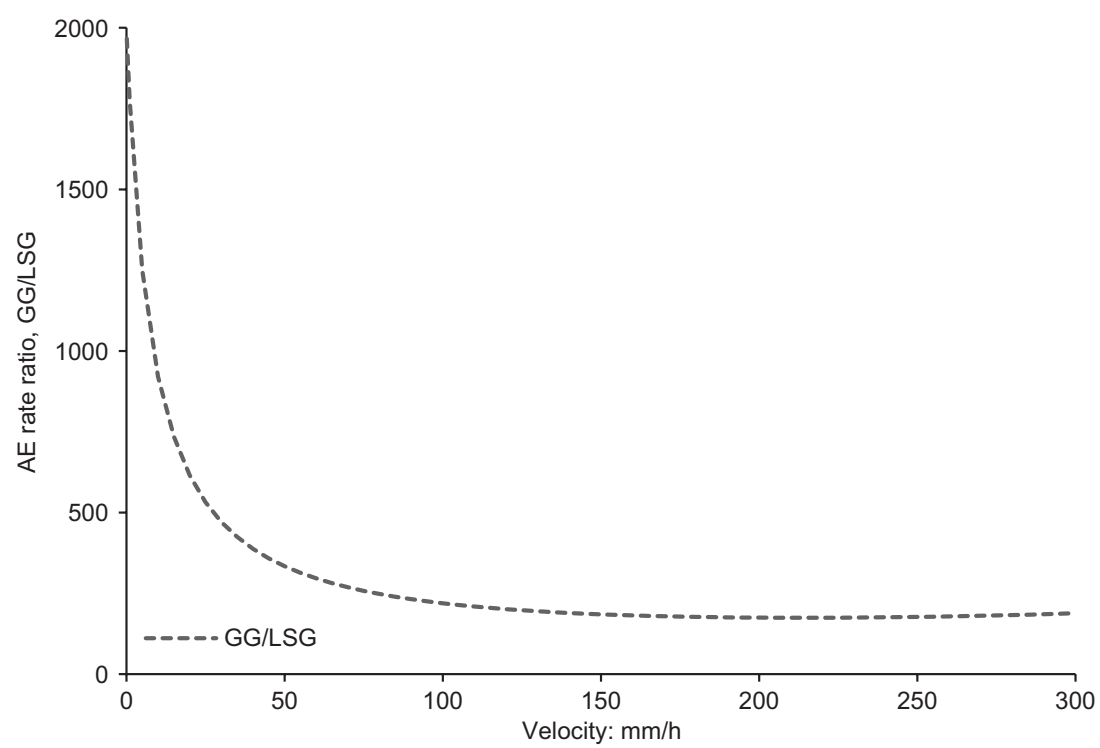

(b)

Fig. 13. Ratio of AE rates generated by the GG backfill to the other backfills plotted against applied velocity: (a) GG/LBS; (b) GG/LSG

displacement rates, which can be used to quantify and communicate accelerations in slope movement during failure (i.e. in the process shown in Fig. 1). A generic relationship has been produced in Fig. 15 by combining the empirical relationships derived from both GG and LBS backfills. This demonstrates that such generic relationships can be defined for groups of different backfill materials, removing the need for specialised calibration of each backfill material used, to quantify order of magnitude changes in slope displacement rates from measured $\mathrm{AE}$ rates, to provide early warning.

The results have revealed that active waveguides experience behaviour comparable to laterally loaded piles when subjected to slope movement. The predominant AE generation mechanism is granular shearing at the shear surface at small magnitudes of deformation; however, the volume of backfill being deformed and the confining pressures in the backfill increase with displacement and this behaviour causes the AE rate-velocity relationship gradient to increase. These results have implications for designing the embedment depth for active waveguide installations, because the position at which the shear surface intersects the active waveguide along its length will govern how it interacts with the host soil (e.g. Poulos, 1995), which will also influence the AE rateslope velocity relationship that it produces. In addition, active waveguides installed in reactivated slopes that experience multiple surge movements will be subjected to cycles of stress and stress relaxation, and their geometry will change over time, modifying the AE rate-slope velocity relationships they produce.

Practical considerations when selecting backfill materials include: ease of compaction around the waveguide to ensure no large voids are present; and the AE propagation distance (i.e. depth to the shear surface) as low-amplitude backfillgenerated $\mathrm{AE}$ will be attenuated before being detected. Relatively single-sized granular soils can be compacted easily around the waveguide, and this is why they are typically used as backfills (Smith et al., 2014a, 2014b; Smith, 2015; Smith \& Dixon, 2015; Dixon et al., 2015a, 2015b). Backfills with large angular particles generate the highest amplitude AE (e.g. Table 3 and Fig. 13), and these are required for slopes with deep shear surfaces to mitigate the attenuation of AE propagating long distances along the steel tube. Particle size also governs the number of particle-particle interactions and how rapidly this number of interactions 


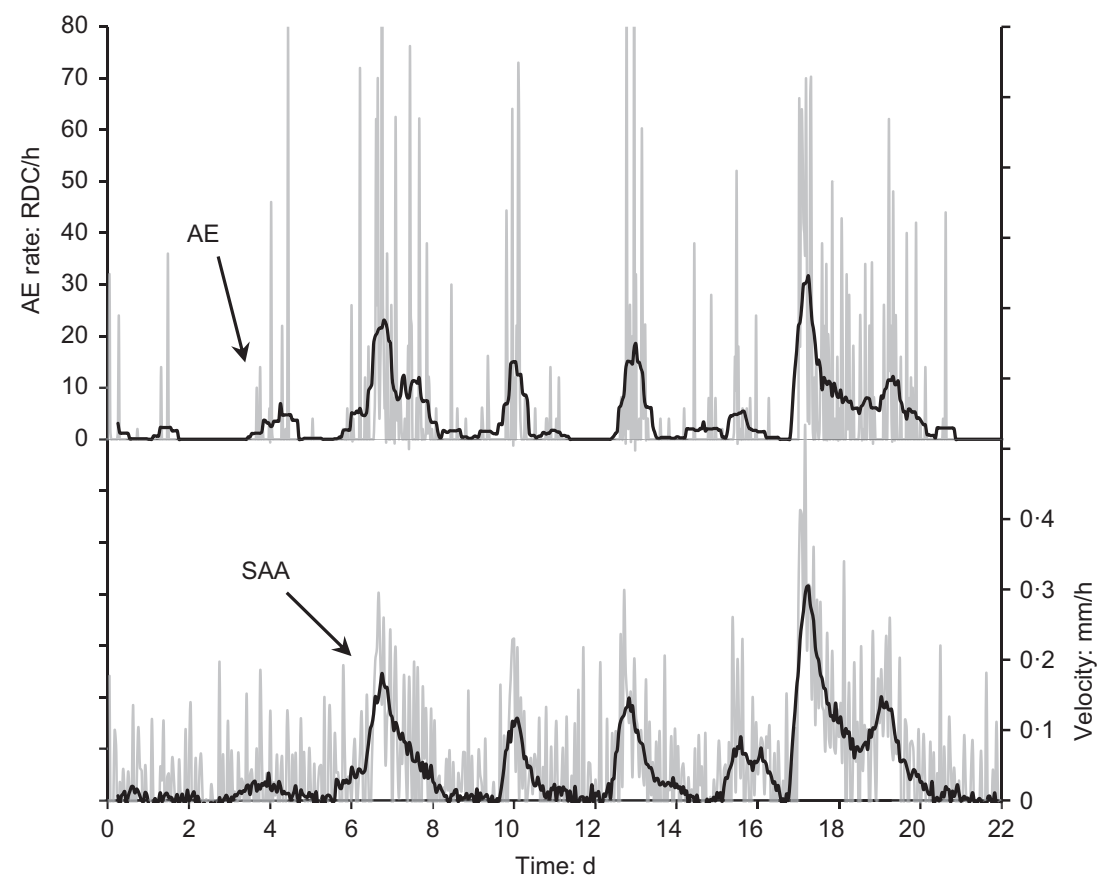

(a)

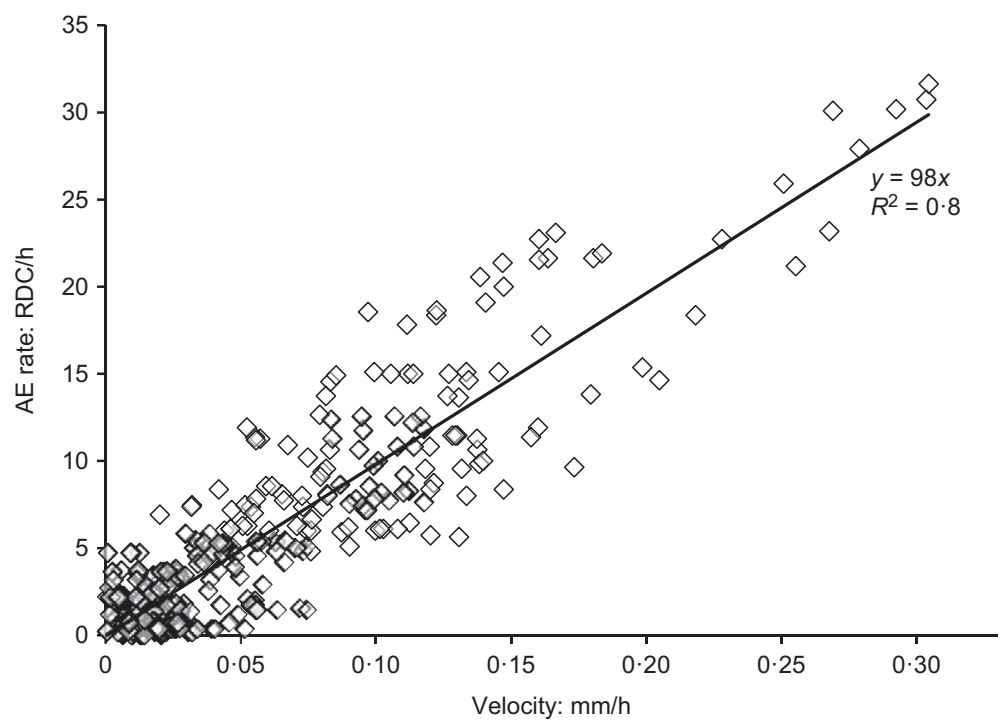

(b)

Fig. 14. AE rate and SAA velocity measurements obtained for a series of reactivated slide events $(<0 \cdot 3 \mathrm{~mm} / \mathrm{h})$ from a field trial reported in Smith et al. (2014a). These data show that $\mathrm{AE}$ monitoring is able to detect slope displacement rates below those examined in this study. (a) AE rate and SAA measured velocity time series measurements (grey lines) and smoothed curves of moving average values (black lines). (b) AE rate plotted against SAA measured velocity relationship derived from the series of reactivated slide events shown in (a) (modified after Smith et al., 2014a)

increases as the backfill volume undergoing deformation increases, which influences the shape of the AE rate-velocity relationship.

The monitored range of $20-30 \mathrm{kHz}$ was selected to ensure the results from this study are relevant to field monitoring applications, which use such a frequency range to minimise background noise. However, monitoring a wider band including lower frequencies would allow AE to be detected earlier; in this study AE below $20 \mathrm{kHz}$ were not detected. It is anticipated that $\mathrm{AE}$ detection would begin at smaller displacements when monitoring a wide frequency band, if well-graded backfills with low void ratio, and large particles with high angularity and high surface roughness, were used. This study has demonstrated that these soil properties (e.g.
Table 3) significantly influence AE generation. These backfills would generate the greatest number of transient $\mathrm{AE}$ events per unit time (i.e. frequency) because they not only have a greater number of particle-particle and particlewaveguide contacts; they also have more particle surface feature contacts that generate AE during relative particle movement.

\section{CONCLUSIONS}

This study was conducted to investigate the potential of using active waveguide-generated $\mathrm{AE}$ measurements to provide an early detection of first-time slope failure. The 


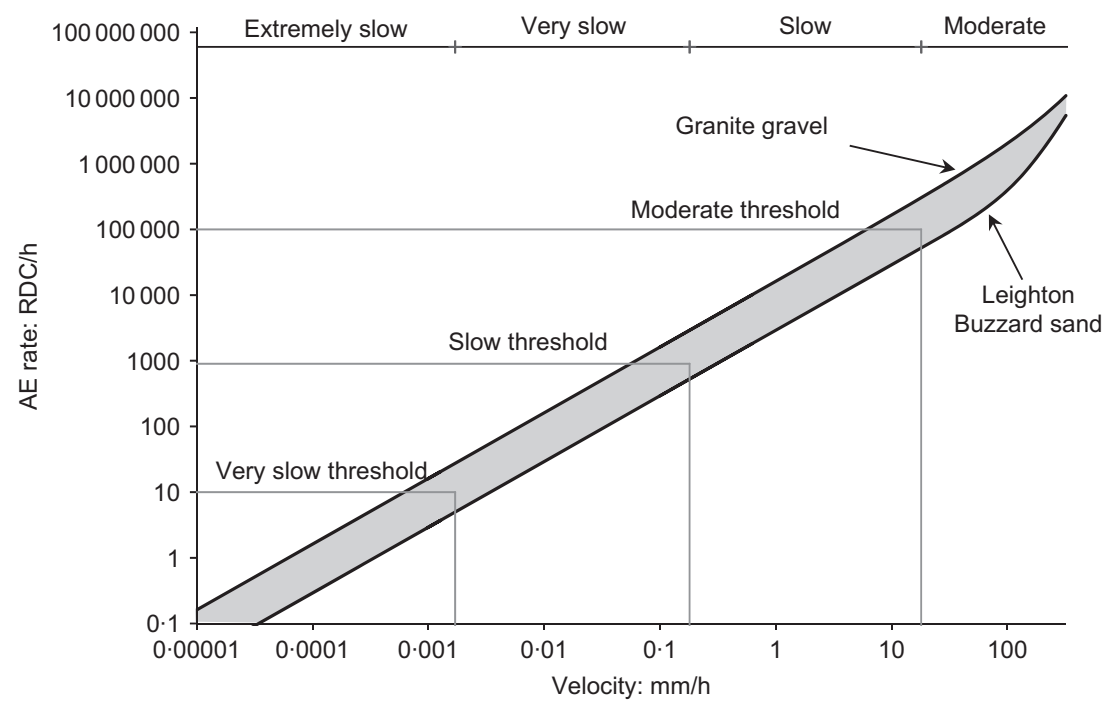

Fig. 15. AE rate-velocity calibration relationships derived for GG and LBS plotted on log scales, with the standard landslide velocity scale (Cruden \& Varnes, 1996) superimposed, demonstrating that generic relationships can be obtained for groups of backfills to determine $\mathrm{AE}$ rate warning trigger levels based on slope displacement rates

principal findings are summarised in the following conclusions.

(a) Evidence has been obtained showing that $\mathrm{AE}$ monitoring of active waveguides can both detect shear surface development and quantify increasing rates of movement during slope failure, thereby providing an early detection of slope instability. The majority of the measurements in this study to support this conclusion were made at displacement rates above $0.5 \mathrm{~mm} / \mathrm{h}$; however, these findings are supplemented by previous research reported by the authors in Smith et al. (2014a), which demonstrates performance of the AE monitoring technique below slope displacement rates of $0.3 \mathrm{~mm} / \mathrm{h}$.

(b) Empirical AE rate-slope velocity relationships have been defined for three different active waveguide backfill types, which allow slope displacement rates to be quantified from measured $\mathrm{AE}$ rates.

(c) Evidence has been obtained showing that generic AE rate-slope velocity relationships can be developed for groups of granular backfill materials, removing the need for specialised calibration of each backfill material employed, which can be used to quantify order of magnitude changes in slope displacement rates from measured $\mathrm{AE}$ rates to provide early detection of slope instability.

(d) The choice of backfill can significantly influence the AE rate-slope velocity relationship, both in terms of magnitude and distribution with time. Backfill with large, angular particles produced AE responses with the greatest magnitude and began generating detectable $\mathrm{AE}$ the earliest. Further research is required to achieve a greater understanding of how the properties of granular soil influence the AE they produce.

\section{ACKNOWLEDGEMENTS}

The support provided by the Engineering and Physical Sciences Research Council (EP/H007261/1, EP/D035325) and Loughborough University is gratefully acknowledged. The authors also acknowledge the collaboration with Philip Meldrum, British Geological Survey, in development of the AE measurement system used in this study, and the excellent technical assistance provided by $\mathrm{Mr}$ Lewis Darwin. Data reported in this study can be made available by the authors on request.

\section{REFERENCES}

Abdoun, T., Bennett, V., Desrosiers, T., Simm, J. \& Barendse, M. (2013). Asset management and safety assessment of Levees and Earthen Dams through comprehensive real-time field monitoring. Geotech. Geol. Engng 31, No. 3, 833-843.

Bromhead, E. N. (2004). Landslide slip surfaces: their origins, behaviour and geometry. In Landslides: evaluation and stabilization (eds W. A. Lacerda, M. Ehrlich, S. A. B. Fontoura and A. S. F. Sayão), pp. 3-21. Boca Raton, FL, USA: CRC Press.

Cavarretta, I., Coop, M. \& O'Sullivan, C. (2010). The influence of particle characteristics on the behaviour of coarse grained soils. Géotechnique 60, No. 6, 413-423, http://dx.doi.org/ 10.1680/geot.2010.60.6.413.

Chandler, R. J. (1984). Recent European experience of landslides in over-consolidated clays and soft rocks. Proceedings of the 4th international symposium on landslides, Toronto, Canada, pp. $61-80$.

Chichibu, A., Jo, K., Nakamura, M., Goto, T. \& Kamata, M. (1989). Acoustic emission characteristics of unstable slopes. J. Acoustic Emission 8, No. 4, 107-112.

Cho, G. C., Dodds, J. \& Santamarina, J. C. (2006). Particle shape effects on packing density, stiffness, and strength: natural and crushed sands. J. Geotech. Geoenviron. Engng 132, No. 5, 591-602.

Cooper, M. R., Bromhead, E. N., Petley, D. J. \& Grants, D. I. (1998). The Selborne cutting stability experiment. Géotechnique 48, No. 1, 83-101, http://dx.doi.org/10.1680/geot.1998.48.1.83.

Cruden, D. M. \& Varnes, D. J. (1996). Landslide types and processes. In Landslides: investigation and mitigation (eds A. K. Turner and L. R. Schuster), TRB special report 247, Ch. 3. Washington, DC, USA: Transportation Research Board.

Dixon, N., Hill, R. \& Kavanagh, J. (2003). Acoustic emission monitoring of slope instability: Development of an active wave guide system. Proc. Instn Civ. Engrs - Geotech. Engng 156, No. 2, 83-95.

Dixon, N., Spriggs, M. P., Smith, A., Meldrum, P. \& Haslam, E. (2015a). Quantification of reactivated landslide behaviour using acoustic emission monitoring. Landslides 12, No. 3, $549-560$.

Dixon, N., Smith, A., Spriggs, M. P., Ridley, A., Meldrum, P. \& Haslam, E. (2015b). Stability monitoring of a rail slope using acoustic emission. Proc. Instn Civ. Engrs - Geotech. Engng 168, No. 5, 373-384. 
Fujiwara, T., Ishibashi, A. \& Monma, K. (1999). Application of acoustic emission method to Shirasu slope monitoring. In Slope stability engineering (eds N. Yagi, T. Yamagami and J. C. Jiang), pp. 147-150. Rotterdam, the Netherlands: Balkema.

Koerner, R. M., McCabe, W. M. \& Lord, A. E. (1981). Acoustic emission behaviour and monitoring of soils. In Acoustic emission in geotechnical practice (eds V. P. Drnevich and R. E. Gray), ASTM STP 750, pp. 93-141. West Conshohocken, PA, USA: ASTM International.

Krumbein, W. C. \& Sloss, L. L. (1963). Stratigraphy and sedimentation, 2nd edn. San Francisco, CA, USA: Freeman and Company.

Lambe, T. W. (1973). Predictions in soil engineering. Géotechnique 23, No. 2, 151-202, http://dx.doi.org/10.1680/geot.1973.23.2.151.

Leroueil, S. (2001). Natural slopes and cuts: movement and failure mechanisms. Géotechnique 51, No. 3, 197-243, http://dx.doi.org/ 10.1680/geot.2001.51.3.197.

Lord, A. E. \& Koerner, R. M. (1974). Acoustic emission response of dry soils. J. Testing and Evaluation (ASTM) 2, No. 3, 159-162.

Michlmayr, G. \& Or, D. (2014). Mechanisms for acoustic emissions generation during granular shearing. Granular Matter 16, No. 5, $627-640$.

Michlmayr, G., Cohen, D. \& Or, D. (2013). Shear-induced force fluctuations and acoustic emissions in granular material. J. Geophys. Res.: Solid Earth 118, No. 12, 6086-6098.

Nakajima, I., Negishi, M., Ujihira, M. \& Tanabe, T. (1991). Application of the acoustic emission monitoring rod to landslide measurement. In Acoustic emission/microseismic activity in geologic structures and materials: proceedings of the 5th conference (ed. H. R. Hardy), pp. 505-519. Pfaffikon, Switzerland: Trans Tech.
Poulos, H. G. (1995). Design of reinforcing piles to increase slope stability. Can. Geotech. J. 32, No. 5, 808-818.

Rouse, C., Styles, P. \& Wilson, S. A. (1991). Microseismic emissions from flowslide-type movements in South Wales. Engng Geol. 31 , No. $1,91-110$.

Skempton, A. W. (1964). Long-term stability of clay slopes, Fourth Rankine Lecture. Géotechnique 14, No. 2, 77-101, http://dx.doi.org/10.1680/geot.1964.14.2.77.

Skempton, A. W. (1985). Residual strength of clays in landslides, folded strata and the laboratory. Géotechnique 35, No. 1, 3-18, http://dx.doi.org/10.1680/geot.1985.35.1.3.

Skempton, A. W. \& Petley, D. J. (1967). The strength along structural discontinuities in stiff clays. Proceedings of the geotechnical conference, Oslo, Norway, vol. 2, pp. 29-46.

Smith, A. (2015). Quantification of slope deformation behaviour using acoustic emission monitoring. PhD thesis, Loughborough University, Loughborough, UK.

Smith, A. \& Dixon, N. (2015). Quantification of landslide velocity from active waveguide-generated acoustic emission. Can. Geotech. J. 52, No. 4, 413-425.

Smith, A., Dixon, N., Meldrum, P., Haslam, E. \& Chambers, J. (2014a). Acoustic emission monitoring of a soil slope: comparisons with continuous deformation measurements. Géotechnique Lett. 4, No. 4, 255-261.

Smith, A., Dixon, N., Meldrum, P. \& Haslam, E. (2014b). Inclinometer casings retrofitted with acoustic real-time monitoring systems. Ground Engng, October, pp. 24-29.

Zheng, J. \& Hryciw, R. D. (2015). Traditional soil particle sphericity, roundness and surface roughness by computational geometry. Géotechnique 65, No. 6, 494-506, http://dx.doi.org/10.1680/ geot.14.P.192. 